\title{
Em busca de boas relações entre artesanato tradicional e design: estudo de caso em Tiradentes, Minas Gerais
}

Ana Luiza Cerqueira Freitas é Doutora em Design, mestre em Engenharia de Produção, graduada em Design Industrial pela FUMA. Trabalha como docente da Escola de Design da Universidade do Estado de Minas Gerais. Autora do livro Design e Artesanato (2017, 2. ed.). Atua no desenvolvimento de projetos, pesquisas, ações de extensão e oficinas nas áreas de processo criativo, design, produção artesanal, memória e valorização de território. Atua como pesquisadora do projeto Estruturação do Sistema de Gestão do Artesanato Brasileiro: diagnóstico e planejamento estratégico, UFMG (2021). <ana.cerqueira@uemg.br> ORCID 0000-0003-3530-2298
Resumo $O$ estudo trata do artesanato tradicional e de sua relação com design, sob a ótica teórica e de campo. 0 trabalho priorizou o estudo de caso com artesãos experientes no exercício de ofícios de modo a identificar e analisar repertórios produtivos próprios do território, bem como compreender métodos de criação e de desenvolvimento de produtos, dinâmicas culturais, e identificar técnicas e preceitos que norteiam os ofícios. O propósito é discutir possíveis relações estratégicas da atividade do artesanato tradicional com o campo de design, considerando o respeito, alteridade, os valores do artesão e seu território de procedência.

Palavras chave Design, Artesanato, Tradição, Conhecimento. 


\section{In search of good relations between traditional handicraft and design: a case study in Tiradentes, Minas Gerais}

Maria Regina Álvares Correia Dias é Doutora em Engenharia e Gestão do Conhecimento, mestre em Engenharia de Produção, ambos pela Universidade Federal de Santa Catarina, graduada em Design Industrial pela Fuma. É professora e pesquisadora da Escola de Design da UEMG nos cursos de graduação, mestrado e doutorado em Design. Coordenou o Programa de Pós-Graduação em Design (PPGD-UEMG) e coordena o Centro de Estudos Teoria, Cultura e Pesquisa em Design. Editora dos Cadernos de Estudos Avançados em Design (2010-2021) e editora-chefe da revista Pensamentos em Design (2021).

<regina.alvares@uemg.br> ORCID 0000-0002-7673-0611
Abstract The study deals with traditional handicrafts and their relationship with design, from a theoretical and field perspective. The work prioritized the case study with experienced craftsmen in the exercise of crafts to identify and analyze own productive repertoires of territory as well as understanding methods of creation and development of products, cultural dynamics, and identify techniques and principles that guide the crafts. The purpose is to discuss possible strategic relations between the activity of traditional handicrafts and the design field, considering respect, alterity, the values of the craftsman and his territory of origin.

Keywords Design, Handicraft, Tradition, Knowledge.

En busca de buenas relaciones entre la artesanía tradicional y el diseño: un estudio de caso en Tiradentes, Minas Gerais

Resumen El estudio aborda la artesanía tradicional y su relación con el diseño, desde una perspectiva teórica y de campo. El trabajo priorizó el estudio de caso con artesanos experimentados en el ejercicio de la artesanía con el fin de identificar y analizar los repertorios productivos propios del territorio, así como comprender métodos de creación y desarrollo de productos, dinámicas culturales, e identificar técnicas y preceptos que orientan la artesanía. El propósito es discutir las posibles relaciones estratégicas entre la actividad artesanal tradicional y el campo del diseño, considerando el respeto, la alteridad, los valores del artesano y su territorio de origen.

Palabras clave Diseño, Artesanía, Tradición, Conocimiento. 


\section{Introdução}

O artigo traz reflexões acerca do repertório produtivo artesanal de caráter tradicional com atenção para os valores relacionados ao artesão e ao seu território de procedência, bem como para a elaboração de estratégias contínuas de proteção e desenvolvimento do setor por meio do design. Com a atenção voltada para a resiliência dos ofícios tradicionais, é plausível afirmar que a atividade é sustentada por um patrimônio que é pessoal para o artesão, calcado no meio ambiente, na utilização de recursos próprios, nos saberes transmitidos de modo tácito, e nas suas relações históricas, socioculturais e técnicas.

A interação entre os modos de produção artesanal e o design se consolida a cada dia, com a perspectiva do artesanato como campo fértil para práticas projetuais e discussões científicas. Neste contexto, surgem reflexões que tratam da aproximação entre estes dois campos de saber. Um dos primeiros pontos a serem observados é aonde se quer chegar, se essa união quer trazer conhecimento ao designer sobre novos processos, ou ao artesão sobre novas oportunidades. "Essa questão define uma linha tênue entre processo e autonomia de ambos." (FREITAS; COSTA; MENEZES, 2008, p. 3)

\section{Artesanato e tradição}

O artesanato é destacado como uma atividade de ocupação humana e econômica. Trata-se não somente da transformação da matéria-prima na criação de objetos, mas também dos aspectos que o caracterizam e a maneira pela qual foi feito.

Cascudo (2000) define artesanato como "objeto utilitário com características folclóricas, não importando o material utilizado; é uma atividade cultural e ocupa lugar de destaque no comércio" (CASCUDO, 2000, p. 26). Aqui é ressaltado o papel econômico da atividade que, conforme Albino (2014), gera divisas. Já segundo Lima (2014), o artesanato tradicional é um conceito amplo que contempla aspectos tangíveis e intangíveis e, portanto, passíveis de interpretações.

\footnotetext{
O objeto artesanal é definido por uma dupla condição: primeiro, o fato de que seu processo de produção é em essência manual. Segundo: a liberdade do artesão para definir o ritmo da produção, a matéria-prima e a tecnologia que irá empregar, a forma que pretende dar ao objeto, produto de sua criação, de seu saber, de sua cultura. (LIMA, 2014, p. 2).
}

Sob a ótica institucional, observam-se alguns dos conceitos elaborados para programas de fomento para o setor, internacionais e nacionais. 0 Programa Artesanias de Colombia, referência de modelo de articulação profí- 
cua para o fortalecimento e promoção do artesanato, considera artesanato

uma atividade criativa e permanente de produção de objetos, realizada com predomínio manual e auxiliada em alguns casos, com máquinas simples obtendo um resultado final individualizado, determinado pelos padrões culturais, o meio ambiente e seu desenvolvimento histórico. (COLOMBIA, 1987, p. 12)

Esta definição se estende ao aspecto do serviço definindo-o como a "aplicação de conhecimentos e habilidades na conservação, reconstrução e extensão de obras e ações que levem a um serviço útil" (COLOMBIA, 1987, p. 12).

No Brasil, o Programa do Artesanato Brasileiro (PAB) define artesanato como "toda produção resultante da transformação de matérias-primas através do emprego de técnicas de produção artesanal, que expresse criatividade, identidade cultural, habilidade e qualidade". (BRASIL, 2018, p. 6). De forma similar o Serviço Brasileiro de Apoio às Micro e Pequenas Empresas (SEBRAE) o define como "toda atividade produtiva que resulte em objetos e artefatos acabados, feitos manualmente ou com a utilização de meios tradicionais ou rudimentares, com habilidade, destreza, qualidade e criatividade (SEBRAE, 2010, p. 12).

Pela lógica do Estado, o conhecimento tradicional está baseado na ideia que as características físicas e identitárias que o constituem são herdadas ao longo de gerações e serão repassadas. Trata-se de regras e representações conhecidas como "herança cultural", cujos conhecimentos são transformados em objetos de memória por mecanismos institucionais e passam a serem armazenados e replicados (INGOLD; KURTTILA, 2018).

Pela lógica do cotidiano local, o conhecimento tradicional é inseparável das práticas de habitar a terra e é nesta relação com o lugar de origem que ele é gerado. A natureza deste conhecimento está dentro da cabeça das pessoas e, portanto, está continuamente ocorrendo. Basicamente, a distinção está em pensar a tradição como um tipo de "substância" e pensá-la como um tipo de "processo" (INGOLD; KURTTILA, 2018, p. 178).

Nugraha (2012) apresenta quatro explicações para a preservação da tradição: a maioria das tradições apoia a localidade e a diversidade, a maioria imita e incorpora a natureza, várias tradições podem desaparecer a qualquer momento, e as tradições tornam-se uma ferramenta para expressar a identidade cultural. Embora por tradição, o artesão preserve formas e estilos, ele pode evoluir e acompanhar as necessidades de melhor uso dos objetos, contribuindo para a formação de novos conceitos e, por que não, iniciar novas tradições, conforme salienta Cascudo (2000).

Bardi (1964) e Magalhães (1985) concordam que não existe no Brasil o artesão típico. Bardi (1994, p. 12) sustenta que o artesanato como corpo social nunca existiu no Brasil. "O que existe é um pré-artesanato doméstico esparso, artesanato nunca", quando se considera o artesão aquele que descende das tradicionais corporações de ofício europeias. Para Magalhães 
(1985, p. 173), considerando o "conceito clássico e ortodoxo, não existe propriamente artesanato no Brasil [...] o artesão brasileiro é basicamente um designer em potencial, muito mais do que propriamente um artesão no sentido clássico".

\section{Artesanato tradicional e design}

Correia (2003, p. 9) observa que "o artesanato foi a primeira forma de ensaiar um pensamento em design e, por isso, pode ser entendido como seu antecessor". Esta colocação converge para a percepção de Magalhães (1995) quando afirma que o alto índice de invenção do artesão brasileiro é uma atitude de "pré-design".

Devemos lembrar que design é projeto; "é uma categoria própria, autônoma, já que se encontra na intersecção entre indústria, mercado, tecnologia e cultura prática da vida cotidiana" (BONSIEPE, 2011, p. 234). 0 design é o oposto da criação arbitrária. A partir de um problema dado, ele elabora conceitos capazes de sintetizar ideias e valores, e traduzir necessidades, sejam econômicas, funcionais, estéticas, simbólicas e ambientais em soluções projetuais.

A instituição mais relevante que rege a área do design - World Design Organization (WDO) - enfatiza o papel do profissional enquanto agente transformador da sociedade. 0 código de ética profissional sugerido pela WDO (2019) enfatiza que "os designers devem se esforçar para incorporar e promover as tradições culturais de suas sociedades nacionais" (WDO, 2019, p. 3).

A abrangência dada atualmente à atividade de design revela um amplo espectro de atuação junto ao artesanato que, neste cenário, se destaca como uma fonte genuína, semântica e produtiva, além de integrar a formação do patrimônio cultural imaterial e material. 0 design voltado para o aprimoramento e evolução da cultura compõe o processo de valorização do território, sua identidade e sua salvaguarda. Trata-se de uma modalidade de intervenção para a formulação de projetos sustentados pelo capital cultural local e que sejam capazes de produzir recursos, gerar fluxo econômico e processos de conhecimento (FRANZATO, 2008).

É importante tem em conta que a produção artesanal autêntica, um complexo de nuances técnicas, estéticas e sociais, é um valioso recurso local em relação ao design e criação de identidade, segundo Bonsiepe (2011). Trata-se geralmente de uma atividade informal de processos produtivos simples e não intensivos de capital.

Aloísio Magalhães ${ }^{1}$ foi pioneiro na proposição de estratégias de desenvolvimento local por meio da convergência de atributos do artesanato tradicional e do design. Ele acreditava na união destes campos de saber como uma valiosa oportunidade de desenvolvimento de um design genuinamente brasileiro (LEITE, 2017). Para Magalhães, o design estava presente em toda 
parte, que não era uma atividade simplesmente estética, formal, e já sugeria uma vasta gama de possibilidades de atuação. "O design pode assumir uma característica mais alargada, cobrindo não somente a projetação dos signos e objetos que nos circundam e com os quais interagimos, mas todo sistema ou processo que se configure como projeto" (LEITE, 2017, p. 13).

\section{Estudo de casos de ofícios tradicionais em Tiradentes, Minas Gerais}

A pesquisa se baseia em estudos de casos realizados por meio de observações e entrevistas. $O$ objetivo é apresentar um panorama do artesanato tradicional e da relação deste com o design. 0 estudo faz parte de uma pesquisa mais ampla de tese de doutorado que abrangeu o território denominado Campo das Vertentes, localizado na região central do Estado de Minas Gerais nas cidades de Coronel Xavier Chaves, Entre Rios de Minas, São João del-Rei, Tiradentes e Vitoriano Veloso. A pesquisa contemplou quatorze casos com diferentes artesãos especializados em sete ofícios tradicionais desse território - ferraria, cerâmica, modelagem de chapa, entalhe e escultura em madeira, marcenaria e pintura, cestaria, trançado, cantaria e escultura em pedra (Figura 1).

Para esse artigo, optou-se pelos estudos de casos de Tiradentes, nos quais destacam dois ofícios tradicionais - ferraria e escultura e entalhe em madeira. As entrevistas converteram-se naturalmente em depoimentos e
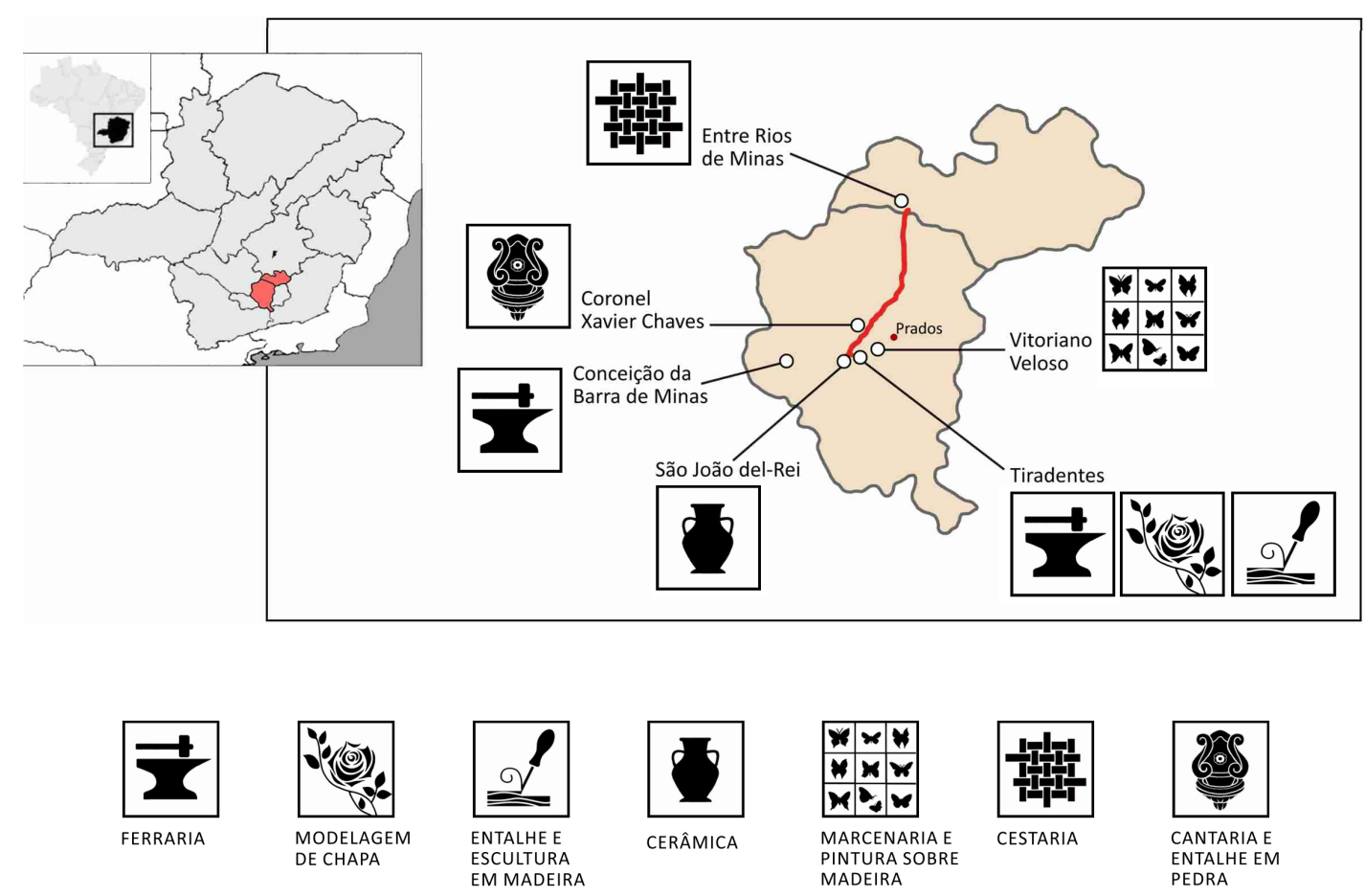

Fig 1. Visão geral da pesquisa empreendida Fonte: Os autores, 2021 
relatos caracterizando-se como História Oral de Vida (MARTINS; THEOPHILO, 2007, p. 95). Foi neste formato de conversa que os artesãos se sentiram mais à vontade com a pesquisadora.

o estudo de caso é uma investigação empírica sobre um fenômeno contemporâneo em seu contexto de vida real, especialmente quando os limites entre o fenômeno e o contexto não são claramente evidentes (YIN, 2010). Esta definição contempla os casos ora apresentados. Os resultados alcançados abrangem a compreensão individualizada de diversos repertórios técnicos balizados pela criatividade direcionada, sistemas produtivos eficientes e baixa tecnologia.

A pesquisa acerca do cotidiano inerente aos ofícios tradicionais deve ser aqui compreendida como uma forma de mapear os valores dos recursos materiais e imateriais que sustentam a atividade, caso a caso. Os critérios adotados para análise dos estudos de casos visam abordar os mesmos pontos para a interpretação e discussão dos dados levantados (Quadro 1).

\section{Parâmetros de análise de dados}

\begin{tabular}{ll}
\hline Trajetória & $\begin{array}{l}\text { Formas de aprendizado e aperfeiçoamento técnico, } \\
\text { reconhecimento }\end{array}$ \\
\hline Processo criativo & Influências culturais e métodos de criação \\
\hline Processo produtivo & $\begin{array}{l}\text { Produto, matéria-prima, ferramentas e instrumentos, } \\
\text { técnica, ritmo, evolução }\end{array}$ \\
\hline Condições de trabalho & Ergonomia, segurança, saúde \\
\hline Comercialização & $\begin{array}{l}\text { Formas e meios de comercialização, divulgação, } \\
\text { feedback dos clientes }\end{array}$ \\
\hline Continuidade do ofício & Métodos de transmissão de saberes, pedagogia \\
\hline Organização & Associações, cooperativas, formas de apoio \\
\hline Ações de design & Compreensão de design, formas de participação \\
\hline
\end{tabular}

Quadro1. Parâmetros

de análise dos dados coletados Fonte: Os autores, 2021
Tiradentes é distante $193 \mathrm{~km}$ de Belo Horizonte e 14 km de São João del-Rei, e localiza-se ao pé da Serra São José, uma área de proteção ambiental e patrimônio histórico. Fundada em 1718, a antiga Vila de São José do Rio das Mortes foi palco de lutas e conflitos políticos decisivos e se destacava pela mineração e pelo comércio. Seus primeiros povoadores foram os paulistas atraídos pelo ouro.

O conjunto arquitetônico e urbanístico de Tiradentes (Figura 2) rendeu-lhe o título de patrimônio histórico nacional em 1938, e é considerado um dos centros históricos de arte barroca mais bem preservados do 
Brasil (IPHAN, 2020). A região integra o Circuito Turístico Estrada Real. Por esta região passou a primeira via aberta oficialmente pela Coroa Portuguesa, século XVII, para ligar o litoral à região produtora de ouro no interior do estado (IER, 2019).

Com cerca de 8.000 habitantes, o município contempla e concatena comercialmente o seu patrimônio histórico, cultural e ambiental, tornando-se um importante centro turístico, de eventos e de produção e comércio de artesanato.

Dentre as suas mais diversas categorias, destaca-se o artesanato tradicional, na produção de ferragens, luminárias, móveis, esculturas, imagens, trançados, utensílios e adornos em geral.

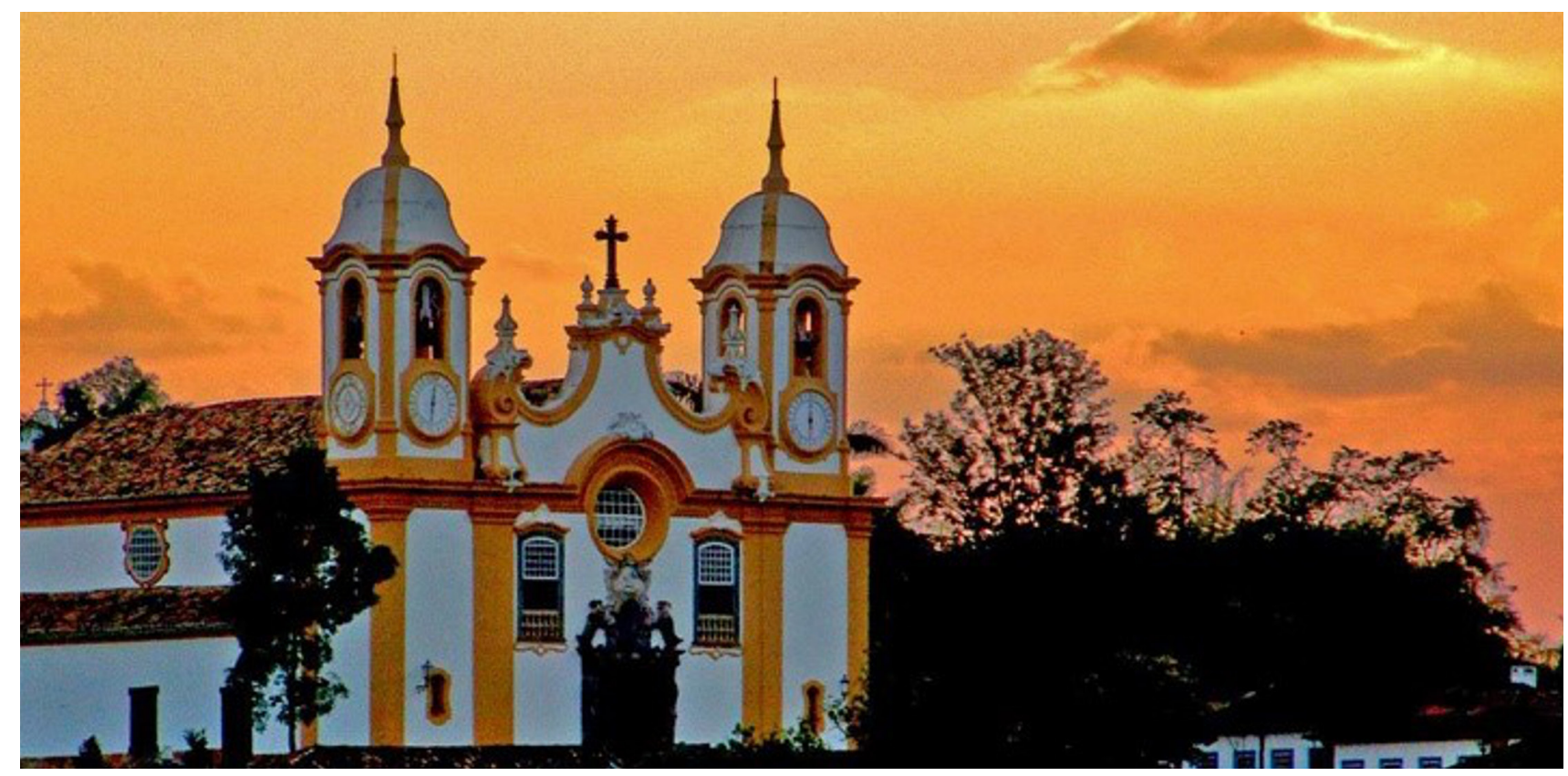

Fig 2. Vista da cidade colonial de Tiradentes

Fonte: Instituto do Patrimônio Histórico e Artístico Nacional.

Disponível em: http://portal.iphan.gov.br/. Acesso em: 2 fev. 2021

Em Tiradentes, foram realizadas cinco entrevistas com os artesãos Luiz Gonzaga França e Luciano Lombello e o aprendiz Daniel Luiz Silva, que se ocupam do ofício da ferraria, e João Goulart Silva e Lucas Santana Silva, que exercem a escultura e entalhe em madeira. 


\section{Os casos do ofício tradicional da ferraria}

A ferraria consiste na conformação do metal aquecido. 0 forjamento é a principal técnica associada à ferraria; é o uso de forças de compressão localizadas. Definido o modelo, o desenho é riscado e o material é cortado. O metal é aquecido na forja até adquirir a maciez adequada, quando então é martelado sobre uma bigorna e conformado como desejado. Esta etapa se repete várias vezes, num processo lento, mas que ao mesmo tempo exige a agilidade do artesão. 0 material esfria rápido, fato que restringe o tempo para modelar.

Na sequência é feita a têmpera que consiste no resfriamento do metal, momento que o material readquire a dureza. Este procedimento geralmente é feito utilizando-se de óleo animal (sebo) ou água. A temperatura de aquecimento certa, o jeito de martelar e a têmpera interferem sobremaneira na qualidade do produto final. A ferraria é uma profissão pesada, que exige mais fisicamente do artesão.

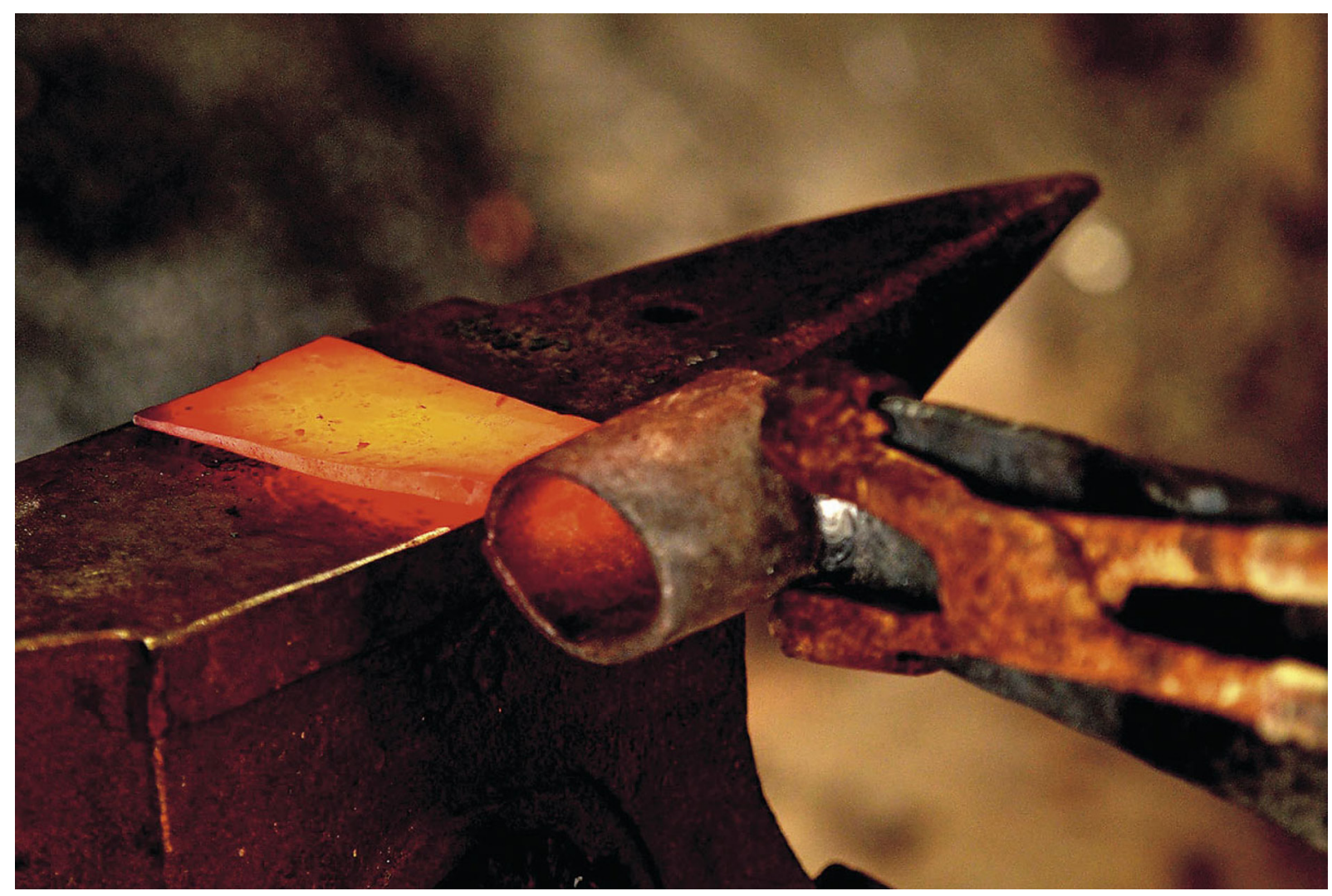

Fig 3. 0 ofício do ferreiro Fonte: Foto de Augusto Pessoa. Disponível em: https:// revistacontinente.com.br/edicoes/145/potengi-a-arte-de--forjar-o-ferro. Acesso em: 2 fev. 2021 
A oficina de ferraria (Figura 3) conta com a forja, geralmente a carvão, a bigorna, torno, furadeira de bancada, morsa de bancada, serra elétrica e manual, solda, e às vezes, um torno. $O$ processo de produção utiliza-se de instrumentos como alicates, martelos, pinças, ponteiras, punções, riscadores. $\mathrm{Na}$ etapa de acabamento, o principal recurso é o esmeril que trabalha o polimento das peças, bem como a manutenção das ferramentas.

\section{Artesãos Luiz Gonzaga França, Luciano Lombelo e Daniel Luiz Silva}

Luiz Gonzaga França, conhecido como Zinho, começou como auxiliar de ourives aos 22 anos e foi se especializando no trabalho com a prata na produção de anéis, e o latão na produção de peças de decoração. Em 1972, o artesão montou sua própria oficina.

Sua produção inicial era de dobradiças e puxadores, tudo feito à mão e com o uso de poucas ferramentas. $O$ artesão relata que nesta época seus serviços foram indicados para um arquiteto que iria restaurar um sobrado na cidade. Para Zinho, este trabalho marcou o início da produção de ferragens voltada para o resgate e restauração da arquitetura colonial.

Os seus primeiros aprendizes foram seus filhos, que atuam cada qual em suas oficinas. Luciano Lombello, seu enteado, também foi seu aprendiz e trabalha com ele desde 1994. Zinho teve muitos aprendizes. Segundo o artesão, a maioria vislumbrava um dia ter a sua própria oficina. 0 processo de ensino-aprendizagem consiste na demonstração do processo de confecção de uma determinada peça, e o aprendiz exercita o ofício por meio da repetição dos procedimentos apresentados pelo mestre.

Daniel Luiz Silva, sobrinho da esposa de Luciano, atua a cinco anos nesta oficina. "Eu aprendi com o Luciano e com o Zinho, que me orientam até hoje". 0 interesse deste jovem artesão-aprendiz pela ferraria, além de vínculos familiares, é em função da grande demanda local para este tipo de produção artesanal. Daniel acredita que o cenário atual do artesanato na cidade e região favoreceu o desenvolvimento de aspectos importantes para o exercício do ofício como condições aquisição de matérias-primas e de comercialização, bem como o valor cultural do ofício.

Em 2001 o artesão foi convidado pelo Sebrae-MG para participar do projeto Resgate Cultural do Artesanato Mineiro e Oficina Viva ${ }^{2}$. Trata-se de uma ação de registro que destaca ofícios artesanais tradicionais em Minas Gerais, bem como da realização de uma oficina para a demonstração do processo de produção. Esta participação trouxe mais reconhecimento para o seu trabalho.

Em 2020, Zinho é o homenageado da quarta edição da Semana Criativa de Tiradentes (SCT). Trata-se de um festival anual que une artesãos experientes procedentes da região dos Campos das Vertentes/MG a designers 
e arquitetos por meio de palestras, exposições, comercialização e oficinas de desenvolvimento de produtos.

Seus principais produtos são fechaduras, dobradiças, cadeados, chaves, trincos, aldravas, dentre outras possibilidades de aplicação da técnica. A comercialização dos produtos é realizada por meio de encomendas feitas diretamente na oficina ou por meios eletrônicos, para dentro e fora do país.

De modo geral, as peças são produzidas a partir de um modelo trazido pelo cliente. A criação é inerente ao processo produtivo haja vista as frequentes adaptações técnicas e de ferramental demandadas em alguns modelos. Na maioria das vezes, as matérias-primas, basicamente chapas e tarugos de ferro, são adquiridas em ferros-velhos e depósitos de materiais da região.

Zinho relata ter criado muitos desenhos, mas ressalta que criar uma peça nova é desanimador porque a cópia por outros artesãos é imediata. Quando questionado sobre a possibilidade de registrar os seus desenhos no Instituto Nacional de Propriedade Intelectual (INPI), o artesão argumenta que este procedimento não tem relevância para ele dada a intensa rotina de produção, o fato de trata-se de uma tipologia de produto condicionada a padrões históricos e artísticos da arquitetura colonial, e a boa reputação do seu trabalho.

Zinho e Luciano chamam a atenção para uma concorrência de baixa qualidade. "Tem cliente que não olha qualidade, ou não sabe olhar. Tem gente que faz uma fechadura e não garante a durabilidade dela. Faz uma mola mais frágil, uma mecânica com folga [...]". De acordo com os artesãos, suas peças têm garantia para mais de 10 anos, pois foram raras as vezes que alguém reclamou do serviço. Para garantir a autoria, a oficina tem um carimbo que prensa sua marca na peça produzida.

Sobre o modo de produção, Luciano destaca que no início o processo era mais braçal, penoso, e que a aquisição de algumas máquinas trouxe mais facilidade, agilidade e melhores condições de trabalho, sem descaracterizar a produção e permitindo um acabamento melhor às peças. No entanto, o artesão chama a atenção para o fato dos clientes, na sua maioria, exigirem a rusticidade na peça para mostrar que é mesmo feito artesanalmente, fato que não se sobrepõe à qualidade final de funcionamento ou acabamento.

A oficina recebe encomendas de todo o Brasil e do exterior. No que tange aos trâmites necessários para a exportação, Luciano relata receber o apoio de um cliente do Rio Grande do Sul que trabalha com móveis de madeira. Além das ferragens para o casario colonial rural e urbano, estes artesãos se atendem a obras de restauração de patrimônio de outras cidades do Estado.

Quanto às condições de trabalho, os artesãos chamam a atenção os cuidados com os olhos e com o ruído que ocorre no decorrer da produção. "Tem que proteger o ouvido e o olho. Tudo é costume. A pessoa acostumou, não deixa de usar as proteções". Os equipamentos de proteção individuais mais usados são as luvas, avental, protetor auricular e óculos de proteção. 


\section{Os casos do ofício tradicional da escultura e entalhe em madeira}

Dentre as técnicas artesanais que envolvem a madeira, a escultura e o entalhe se destacam pela manualidade e consistem basicamente em abrir sulcos na peça com ajuda de ferramentas que podem resultar como produto final peças artísticas, imagens sacras, objeto utilitários, e ornamentação.

A forma de trabalho e as ferramentas usadas (Figura 4) variam de acordo com o desenho e o tamanho da peça produzida e com a preferência e habilidade do artesão. Normalmente, primeiro são usados machado, serras, serrotes e facões para colocar a peça no tamanho adequado ao artefato a ser produzido.

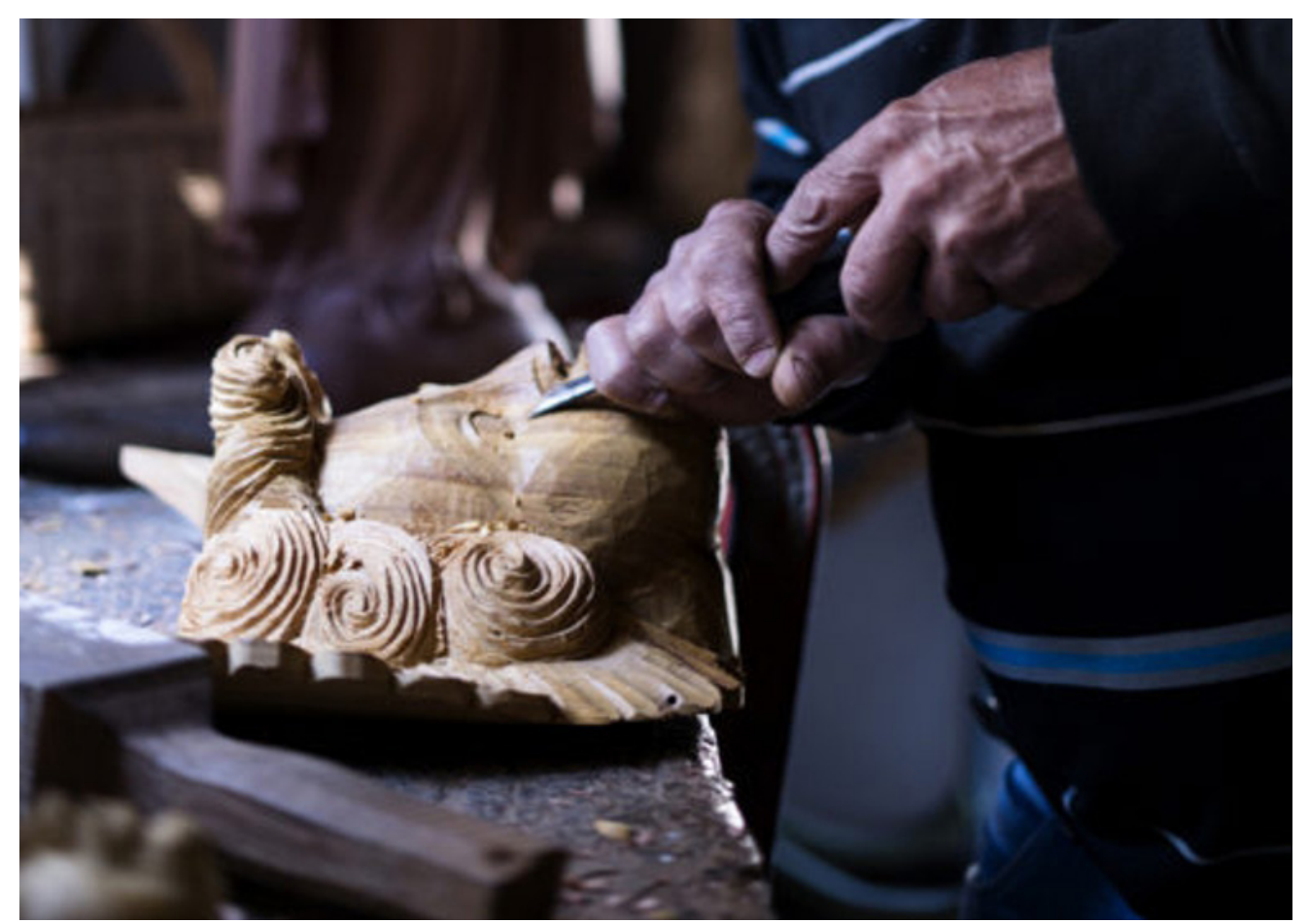

Fig 4.0 ofício escultor e entalhador

Fonte: Foto de João Bertholini. Disponível em: https:// semanacriativadetiradentes. com.br/exposicoes-2019/.

Acesso em: 2 fev. 2021

Com o enxó, enxó-goiva, enxó-reto, alegra, as madeiras são escavadas. As plainas e raspilhas são usadas para retirar excesso de material. Já os formões de diversos tipos são acionados com a maceta, uma espécie de martelo de madeira, para esculpir a peça. Depois goivas, grosas e lixas são usadas para dar o acabamento e deixar a peça mais uniforme em alguns casos, quando assim desejado. Algumas peças são esculpidas com canivetes e "faquinhas" feitas pelos próprios artesãos. Pode ser dado o acabamento na peça com selador, verniz, óleo, cera, sebo e outros agentes.

Algumas vezes o próprio artesão vai coletar a matéria-prima e a sua decisão de qual irá recolher passa por aspectos técnicos como a época de 
cortar, qual é a propriedade especifica de cada material relativo ao objeto a ser desenvolvido, e ao formato da madeira que pode, às vezes, induzir a criação de algumas peças. Outras vezes os artesãos, não possuindo a matéria-prima disponível in natura, recorrem à compra do material.

\section{Artesãos João Goulart Silva e Lucas Santana Silva}

Conhecido como Jango, mestre santeiro, João Goulart Silva começou como ourives em Tiradentes na década de 1970. Com o declínio desta atividade, Jango passou a trabalhar em uma marcenaria, onde atuava como torneiro. Foi neste ambiente que o artesão, aos poucos, começou a esculpir. "Sem saber, sem nada, eu peguei um pedaço de madeira e comecei. Peguei um toco e esculpi o rosto de Cristo". No início da década de 1980 foi realizada uma exposição na cidade. Com a ajuda de amigos que divulgaram suas primeiras esculturas, o artesão foi convidado para expor o seu trabalho. "Aí deu certo, fez sucesso e eu não parei mais".

Jango trabalha sozinho, um aspecto ainda mais característico desta técnica de marcante viés artístico. Eventualmente conta com a colaboração do filho Lucas Santana Silva, também escultor e entalhador, e que o acompanha desde os nove anos de idade. Do mesmo modo que Jango, Lucas trabalha sozinho, mas diz que procura sempre estar perto do pai.

Os dois se dividem entre uma pequena oficina na cidade de Tiradentes e outra instalada no sítio da família. A primeira, anexa à sua residência na cidade, é pequena, mas atende à produção de algumas peças, bem como é um espaço onde o artesão recebe visitantes e demonstra o seu trabalho. A segunda oficina é distante $12 \mathrm{~km}$ da cidade e é maior e mais estruturada. 0 equipamento de proteção individual mais usados são os óculos de proteção.

\footnotetext{
Os dois trabalham aqui, eu e o Lucas. Eu gosto mais é de trabalhar na roça. Aí ele acha ruim que eu fique muito lá, e que as pessoas precisam de me ver trabalhando. Mas eu acho que, além disso, ele gosta é de ficar perto para ir pegando as técnicas. Eu gosto disso. (João Goulart Silva, 2019)
}

Sobre a transmissão da técnica, o artesão diz ter gosto em ensinar, acredita no interesse dos mais jovens e relata ser procurado por pessoas de diferentes faixas etárias. As pessoas de fora querem aprender mais por hobby, e as pessoas da região querem aprender e empreender na atividade. Para Jango, o interesse por este tipo de atividade é da pessoa e vem da aptidão. Lucas acredita na vocação e na persistência, desde que a pessoa seja estimulada ainda nova e entende que o desinteresse que há dos mais jovens está relacionado à grande competitividade do mercado de Tiradentes. Os artesãos estimam que no município existem atualmente em torno de duzentas oficinas no segmento de móveis, considerando os grandes e pequenos produtores.

As principais madeiras utilizadas são o cedro, vinhático, jacarandá 
e sibipiruna e jequitibá. Jango destaca a resistência desta madeira ao ataque de carunchos. $O$ artesão afirma não fazer qualquer tipo de tratamento na madeira e relata nunca ter tido reclamações de seus clientes. De acordo com ele, "as imagens das igrejas de Tiradentes têm 200, 300 anos e são de cedro". A aquisição de matéria-prima é feita em São João del-Rei. A compra é feita nas grandes serrarias, onde as partes adquiridas não têm serventia e, por vezes, são consideradas como resíduos. Ocasionalmente eles ganham madeiras de árvores derrubadas pelo vento.

$\mathrm{Na}$ produção de Jango prevalecem as esculturas de santos e anjos. Sobre o seu processo de criação, ele explica: "Quando se trata de uma encomenda o cliente fala o que quer. Eu quero um São José. A gente pega o toco da madeira e já vê ali dentro o que é que vai sair [...] Eu mesmo faço o desenho e passo para a madeira. Os santos a gente já sabe como faz; a gente conhece a história deles". Quando não tem encomenda, o artesão diz fazer o que lhe vem à cabeça. A preferência de Lucas é pela produção de anjos e pelo entalhe que é aplicado em molduras, oratórios, mobiliário, seguindo o estilo sacro e colonial.

Sobre a questão da cópia, Jango não demonstra preocupação. "A escultura é mais difícil de copiar. $O$ entalhe é mais fácil; é mais padrão. Eu tenho o meu traço. Se copiarem, eu invento outra coisa". Ele revela que a inspiração para o seu trabalho vem da sua própria cidade. "Os monumentos, as igrejas [...] o próprio lugar inspira essa cultura, essa arte. E se não fosse isso, aqui seria bem diferente, bem pacato".

As peças são comercializadas por meio de encomendas feitas pessoalmente ou pelas redes sociais e e-mail, ou por meio de exposições. Os produtos são entregues diretamente para os clientes, que vão buscá-los na sua oficina, ou são enviados pelos correios ou por transportadoras. Lucas enfatiza que quando o turista vê o artesão trabalhando, ele tem mais interesse em adquirir a peça. "O melhor marketing".

Para estes artesãos, o design pode ajudar nas áreas de venda, divulgação e incentivo à criação. Na ocasião da entrevista, em 2019, Jango foi homenageado na Semana Criativa de Tiradentes (SCT). "É difícil responder como os designers ajudam na criação. Essas coisas acontecem na hora, ali". Nesta edição do evento, Lucas foi convidado a participar das oficinas, onde desenvolveu novos trabalhos. A ação foi conduzida pelos designers participantes e o resultado deste trabalho derivou em encomendas e na participação na Feira de Decoração e Utilidades Domésticas (ABUP), realizada na cidade de São Paulo. Segundo o artesão, a experiência foi positiva e estimulante. Lucas comenta que "o designer gosta mais quando não tem forma mesmo, quando não dá para saber o que é; mais abstrato". 


\section{Discussão dos casos}

O foco dos estudos de casos foi compreender o lugar demarcado para investigação acerca do artesanato tradicional, tendo em conta suas características técnicas, produtiva, históricas, socioculturais e comerciais, bem como os métodos de desenvolvimento de produtos e de transmissão de saberes inerentes a cada artesão.

No artesanato tradicional prevalece a presença do conhecimento tácito na formação e no aprimoramento no ofício. $O$ artesão desenvolve desde novo a capacidade de aprender com os olhos - observando, e com as mãos - fazendo e experimentando, constituindo-se, dessa forma, em um aprendizado empírico.

Os entrevistados percorreram as mesmas etapas de familiarização com a matéria-prima e com a técnica desde a infância ou a adolescência. Este percurso associado à vocação evoluiu para o aprimoramento profissional contínuo caracterizado pelo autodidatismo. No caso da presença de ajudantes ou de aprendizes, as técnicas são repassadas conforme os preceitos tacitamente estabelecidos, quais sejam, novamente, a repetição, a prática e a observação.

No desenvolvimento de produtos, os artesãos transitam confortavelmente entre a ideação e a prototipagem. 0 domínio da técnica é tamanho que conseguem facilmente materializar o que lhes vem à mente, um atributo que fascina o designer. Estes artesãos trabalham dentro de padrões estabelecidos no século XVII e XVIII. A questão da cópia pelos concorrentes não é relevante, e eles se justificam justamente por trabalharem dentro destes padrões estéticos e pela garantia de oferecer um produto ou um serviço autêntico e de qualidade.

Nos casos estudados prevalecem a criatividade matérica, técnica e simbólica, simultaneamente. A criatividade matérica é caracteriza o conhecimento e a influência da matéria-prima na concepção do produto pelo artesão. A criatividade técnica é caracterizada pela fabricação em si, e neste sentido, chama atenção a rotina de criação e adaptação de ferramentas realizadas no decorrer do processo produtivo. A criatividade simbólica é aqui considerada como decorrente das influências ambientais, socioculturais e históricas do território, sejam estas funcionais e/ou estéticas. Nos casos dos ofícios estudados, estes também estão associados ao patrimônio arquitetônico como recurso técnico de conservação.

As matérias-primas são obtidas na própria região. Na produção prevalece o trabalho individual. Quanto às condições de trabalho, foi verificado o uso contínuo de equipamentos de proteção individual, de acordo com a demanda de cada ofício. Os entrevistados relatam estar atentos aos cuidados com segurança, carregamento e movimentação. $O$ aspecto que mais se destaca é a satisfação na execução do trabalho. Nenhuma queixa quanto à prática do ofício foi relatada.

Outra condição importante é o mercado favorável. Tiradentes é polo de turismo no Estado de Minas Gerais. A região recebe turistas nacionais e estrangeiros durante todo o ano conduzidos por uma extensa agenda de eventos diversos voltados para a gastronomia, música, fotografia, arte- 
sanato, tradições locais e religiosas e que contam com o apoio permanente de instituições públicas e privadas e da sociedade civil. Além da venda direta para o consumidor, a comercialização por meios digitais tem contribuído sobremaneira e todos os entrevistados já instituíram as vendas on-line.

\section{Artesanato tradicional e design: considerações finais}

A pauta desta reflexão reside nas possibilidades de contribuição recíproca entre artesãos e designers tanto para a proteção quanto para o desenvolvimento de ofícios artesanais. Nestes casos, há de se considerar os valores que tais atividades portam, que são decodificados no objeto e estão embutidos em processos produtivos individualizados, onde o artesão é o detentor e transmissor do conhecimento.

O interesse nesta aproximação é maior para o designer. A constatação é em função dos depoimentos dos artesãos e da fundamentação teórica. A maioria dos artesãos apresenta desconhecimento sobre as possibilidades de contribuição do design para o setor. Sob a ótica dos entrevistados, o interesse é quase inexistente. Todos se apresentam como autossuficientes e não apresentam problemas quanto à falta de demanda pelo seu trabalho. Nestes casos, o artesão trabalha de acordo com a matéria-prima, ideias e padrões próprios, necessidades locais, e para atender a encomendas específicas.

Foram identificados atributos e competências genuínas do saber-fazer artesanal acerca do processo criativo, processo produtivo, técnica, significação cultural, matéria-prima, a visão do território, e aspectos referentes ao desenvolvimento dos sentidos e as relações humanas.

Para o artesão de tradição, o design pode contribuir para no fortalecimento das raízes tradicionais do local ajudando-o a melhorar o seu produto, a promover a apropriação de seus valores materiais e imateriais e, dessa forma, ensejar os núcleos familiares envolvidos na produção. Para o designer, este adquire um novo olhar sobre o seu próprio trabalho e se aproxima do domínio de todas as etapas do processo. Desse modo, ampliam-se as suas perspectivas projetuais e processuais, pois ao estar ciente desse processo, 0 designer pode se utilizar dele como forma de obter determinado resultado que não conseguiria se utilizasse a produção industrial.

\footnotetext{
1. Aloisio Magalhães (1927-1982) foi artista plástico e uma das mais importantes figuras do design gráfico no Brasil durante as décadas de 1960 e 1970. No final da década de 1970, Magalhães ganha destaque na carreira de dirigente cultural na esfera pública. Segundo Cardoso (2004, p. 197), Magalhães foi um hábil articulador político e projetou a atividade de design e a cultura brasileira na esfera pública.

2. Além da ferraria em Tiradentes, em 2001 o projeto contempla os ofícios de cantaria em Ouro Preto, cerâmica Saramenha em Ouro Branco, coco e ouro em Diamantina, esteiras pintadas em Santa Luzia, mantas de lã em Itamonte, máscaras da Folia de Reis em Muzambinho, sanfonas em Laranjal, tambores e caixas em Minas Novas, tecelagem figurativas em Uberlândia (SEBRAE, 2001)
} 


\section{Referências}

ALBINO, Cláudia Regina da Silva Gaspar de Melo. Os sentidos do lugar: valorização da identidade do território pelo design. Tese (Doutorado em Design) - Universidade de Aveiro, Aveiro, 2014.

BARDI, Lina Bo. Tempos de grossura: o design no impasse. São Paulo: Instituto Lina Bo e P. M. Bardi, 1994.

BONSIEPE, Gui. Design, cultura e sociedade. São Paulo: Blucher, 2011.

BRASIL. Ministério da Indústria, Comércio Exterior e Serviços. Portaria No 1.007-SEI: Base conceitual do artesanato brasileiro. Diário Oficial da União: Brasília 11 ago. 2018.

CARDOSO, Rafael.Uma introdução à história do design. São Paulo: Blucher, 2004.

CASCUDO, Luís da Câmara. Dicionário do Folclore Brasileiro. 9. ed. São Paulo: Global, 2000.

COLOMBIA. La ley del artesano. In: Ministerio de Desarrollo Económico, Bogotá, 1987. Disponível em: http://www.artesaniasdecolombia.com.co/Documentos/Contenido/468_ artesanias-ley-artesano.pdf. Acesso em: 20 out. 2019.

CORREIA, Susana. Design e Artesanato. In: Cadernos de Design - A alma do design. Lisboa: Centro Português de Design, 2003. p. 8-15.

FRANÇA, Luiz Gonzaga. Trajetória no ofício de ferreiro: Mestre Zinho. [Entrevista cedida a Ana Luiza Cerqueira Freitas]. Conceição da Barra de Minas (MG), 2 h. de duração, 08 jan. 2020.

FRANZATO, Carlo. Design dei Beni culturali nel progetto territoriale. Tese (Dottorato di Ricerca in Design e tecnologie per la valorizzazione dei beni culturali - XX ciclo) - Politecnico di Milano, Milão, 2008.

FREITAS, Ana Luiza Cerqueira; COSTA, Andreia; MENEZES, Marlette. O design e a produção artesanal na pós-modernidade. In: Anais $8^{\circ}$. Congresso Brasileiro de Pesquisa e Desenvolvimento em Design. São Paulo: Centro Univ. Senac, 2008, 08-11 out. 2008. p. 1-5.

IER. História; Caminhos; Cidades. In: Instituto Estrada Real. Belo Horizonte: Instituto Estrada Real/FIEMG. Disponível em: http://institutoestradareal.com.br /estrada real. Acesso em: 05 dez. 2019.

INGOLD, Tim; KURTTILA, Terhi. Percebendo o ambiente da Lapônia finlandesa. ICampos Revista de Antropologia Social. Curitiba: UFPR, v. 19, n. 1. p. 169-182, jan-jun, 2018.

IPHAN. Tiradentes (MG). In: Instituto do Patrimônio Histórico e Artístico Nacional, Disponível em: http://portal.iphan.gov.br/pagina/detalhes. Acesso em: 11 ago. 2020.

LEITE, João de Souza (org.) Aloísio Magalhães. Bens culturais do Brasil: um desenho projetivo para a nação. Rio de Janeiro: Bazar do Tempo, 2017.

LIMA, Ricardo. Cinco pontos para discussão. In: Instituto do Patrimônio Histórico e Artístico Nacional. Brasília: IPHAN, 2014. Disponível em: http://portal.iphan.gov. br. Acesso em 13 set. 2018. 
LOMBELLO, Luciano da Silveira. Trajetória no ofício de ferreiro. [Entrevista cedida a Ana Luiza Cerqueira Freitas]. Tiradentes (MG), 10 jan. 2020, com 1 hora e 30 minutos de duração, 2020.

MAGALHÃES, Aloísio. E Triunfo? A questão dos bens culturais no Brasil. Rio de Janeiro: Nova Fronteira; Brasília: Fundação Pró-Memória, 1985.

MARTINS, Gilberto de Andrade; THEÓPHILO, Carlos Renato. Metodologia da investigação científica para ciências sociais aplicadas. São Paulo: Atlas, 2007.

NUGHARA, Adhi. Transforming tradition: a method for maintaining tradition in a craft and design context. Helsinki: Aalto University Publication, 2012.

SEBRAE - Serviço Brasileiro de Apoio às Micro e Pequenas Empresas. Termo de Referência - Atuação do Sistema Sebrae no Artesanato. Brasília: SEBRAE, 2010.

SEBRAE - Serviço Brasileiro de Apoio às Micro e Pequenas Empresas. Mestres Minas, Ofícios Gerais - resgate cultural do artesanato mineiro. Belo Horizonte: SEBRAE, 2001.

SILVA, Daniel Luiz. Aprendiz de ferreiro. [Entrevista cedida a Ana Luiza Cerqueira Freitas]. Entre Rios de Minas (MG), 08 jan. 2020, com 1 hora de duração, 2020.

SILVA, João Goulart. Trajetória no ofício de escultor e entalhador em madeira. [Entrevista cedida a Ana Luiza Cerqueira Freitas]. Tiradentes (MG), 27 jul. 2019, com 2 horas de duração, 2019.

SILVA, Lucas Santana. Trajetória no ofício de escultor e entalhador em madeira. [Entrevista cedida a Ana Luiza Cerqueira Freitas]. Tiradentes (MG), 07 jan. 2020, com 1 hora e 30 minutos de duração, 2020.

WDO - World Design Organization. Definition of industrial design; Code of professional ethics. Disponível em: https://wdo.org/. Acesso em 13 set. 2019.

YIN, Robert K. Estudo de caso: planejamento e métodos. 4. ed. Porto Alegre: Bookman, 2010. 